\title{
EXPLOITATION POLICY IN THE ASPECT OF INDUSTRY 4.0 CONCEPT - OVERVIEW OF SELECTED RESEARCH
}

doi:10.2478/mape-2018-0045

Date of submission of the article to the Editor: 04/2018 Date of acceptance of the article by the Editor: 07/2018

MAPE 2018, volume 1, issue 1, pp. 353-359

\author{
Assoc. Prof., PhD., Eng. Anna Timofiejczuk \\ Assoc. Prof., PhD., Eng. Jaroslaw Brodny \\ Assoc. Prof., PhD., Eng. Andrzej Loska \\ Silesian University of Technology, Poland
}

\begin{abstract}
The article is a review of completed research on developed and implemented innovative and technologically advanced technical systems. According to the Industry 4.0 concept they can have a significant impact on the efficiency of production processes and product development. In this perspective, the key aspect seems to be maintenance management of technical systems, realized both in the operate phase as well as during service and repair works. There were discussed research results of authors and developed application solutions supporting decision-making processes, in terms of three main periods of realization of exploitation processes: short, medium and long-term.
\end{abstract}

Keywords: maintenance, context based reasoning, OEE, taxonomy methods

\section{INTRODUCTION}

The comprehensive development of production and a product is planned and implemented in the concept of Industry 4.0. This concept, initiated in 2011 as an integral part of the project „High-Tech Strategy 2020 for Germany” (Kagermann, 2014), became the basis of the socalled the fourth industrial revolution or the industry of the fourth generation, which:

- assumes the existence of intelligent systems, which are vertically linked with other processes within the company and horizontally associated with networks creating value,

- is an intelligent combination of many technologies IT used in enterprises,

- is a complex set of solutions resulting from the connection of engineering, computer science and management,

- leads to close computerization of traditional branches of industry and gradually erasing the differences between individual factories.

From the very beginning, the Industry 4.0 concept was open and presented a-priori, which allowed for a wide and varied development of scientific ideas as well as practical applications. The key component connecting most of the interpretations of the Industry 4.0 concept is CPS (Cyber-Physical Systems). CPS is an integrator of the industrial real world and its virtual environment and its purpose is enabling communication of employees, industrial infrastructure and cyber-physical systems. In this aspect, relevant and possible to use the following model and tool solutions, such as: Internet of Things, Internet of Service, Smart Factory, Smart Product. These solutions are supported by technologies for aquiring, gathering, processing and sharing data, such as big data or cloud computing (Hermann et al., 2016).

Apart from the undoubted potential benefits of the concept of Industry 4.0, attention should be paid to emerging constraints at the same time. One of the most important problems that can significantly affect the effective implementation of the described assumptions is related to unreliability of individual components of developed and implemented technical solutions, which are the basis for the implementation and support of innovative and intelligent activities 
in relation to production processes and products. Such unreliability results directly from physical phenomena and organizational conditions of exploitation of technical systems. In particular, the use of technologically advanced technical solutions, generates operate and service problems, contributing to increase the degree of wear of particular elements. As a result, there are unintended exploitation events that have an impact on the decrease in the operate efficiency and constraints in the manufacturing process (Szczesniak et al., 2017).

Therefore, in addition to the development and implementation of innovative and technologically advanced solutions, that have a significant impact on the efficiency of production processes and product development, the key aspect seems to be maintenance management activities realized both in the operate as well as in the service phase (Loska and Paszkowski, 2018; Antosz, 2018; Karwot et al., 2016).

In view of the above arguments, later in this article, there were discussed the authors' research and developed tool solutions supporting decision-making processes in terms of three main periods of realization of exploitation processes, in particular:

1. The short-term assessment of the object technical condition with the use of context based methods.

2. The mid-term assessment of exploitation processes with the use of OEE indicator.

3. The long-term assessment of the exploitation policy with the use of taxonomic methods.

\section{THE SHORT-TERM ASSESSMENT OF THE OBJECT TECHNICAL CONDITION WITH THE USE OF CONTEXT BASED METHODS}

The exploitation policy realized in the short-term period usually has a dispatcher's character and consists in choosing a way of exploitation procedure in relation to a particular technical object within a single maintenance cycle (Burduk, 2013; Kosicka, 2018). For this reason, the decision-making process for this period is based on the diagnostic assessment of the technical condition of machinery and equipment. In such assessment, especially in the inference process, it is important to dispose not only the data resulting from the signal analysis, but also the context of the object's, in the form of information on operating conditions and environmental characteristics. It should be emphasized that the context of the object's operation is often unknown, and its inclusion requires the necessity of its identification (Przystalka et al., 2014; Wachla et al., 2016).

Therefore, there was elaborated methodology of identification of context of exploiting object and identification of associations occurring within this context. The general scheme of the methodology was presented on Fig. 1.

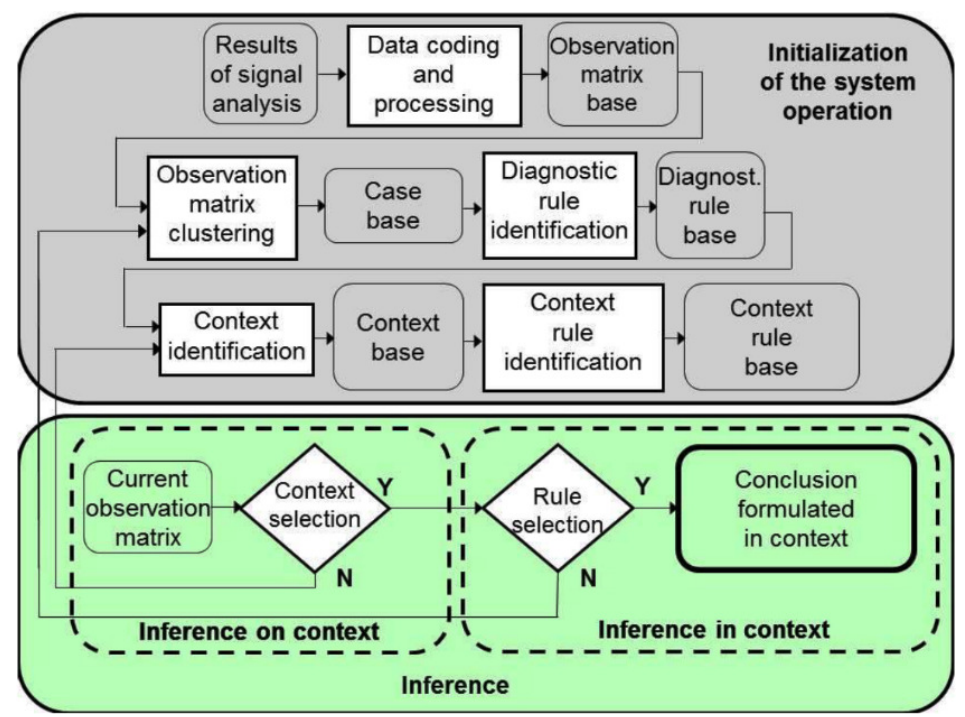

Fig. 1. The general scheme of the context based methodology

Source: (Timofiejczuk, 2013). 
The implementation of the methodology, as well as the functioning of the system based on it, relies on:

1. initialization, i.e. processing data from observation and analysis of signals (data has been subjected to coding, grouping and identification of contexts),

2. inference, on context (selection of contexts, in which the results of signal analysis are considered), in context (selection of a specific range of knowledge consistent with the characteristics of selected contexts).

The result of inference using the developed and verified method is a statement about the condition of the object and the corresponding diagnostic rule. The condition is described by associations between the characteristics of signals observed during the operation of the object.

\section{THE MID-TERM ASSESSMENT OF EXPLOITATION PROCESSESS WITH THE USE OF OEE INDICATOR}

The exploitation policy realized in the mid-term period applies to building and verification of service plans and procedures, including mutual interactions of technical objects, for several maintenance cycles. The decision-making process for this period is based on the assessment with indicators, describing the technical, economic and organizational features of exploiting technical objects and functioning maintenance staffs, including OEE or KPI (JasiulewiczKaczmarek et al., 2017).

OEE is in principle a measure of TPM strategy, but it is also used independently. With this case we are dealing in coal mining (Stecuła et al., 2017b). In particular, the focus was on the assessment of the degree of use of machines used in the exploitation process. To this end, there was developed a pilot support system for the purpose of monitoring the operational efficiency of a mechanized longwall system (Stecuła et al., 2018; Stecuła et al., 2017a). The functioning of the system consists in the analysis of the components of the OEE indicator, based on data obtained in real time from industrial automation systems and processed by developed algorithms (Brodny and Tutak, 2018). The system was based on a data warehouse built with a multi-layered structure, including:

- raw source data layer,

- selected and standardized data layer,

- processed information layer.

Exemplary screens of developed support computer system were shown on Fig. 2.

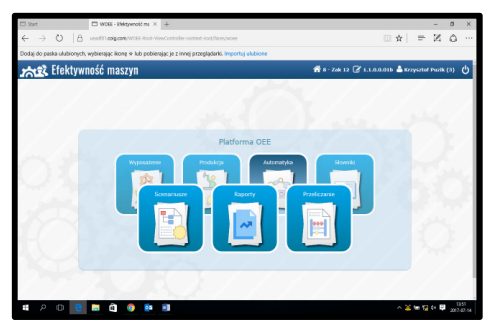

C.

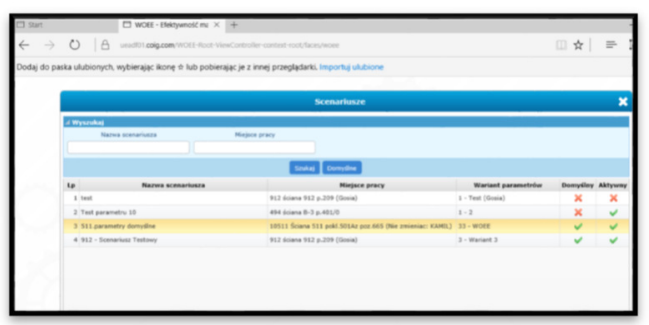

b.

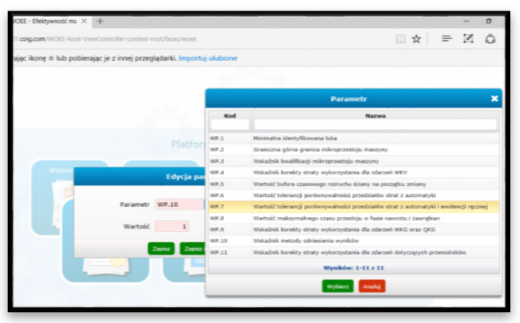

d.

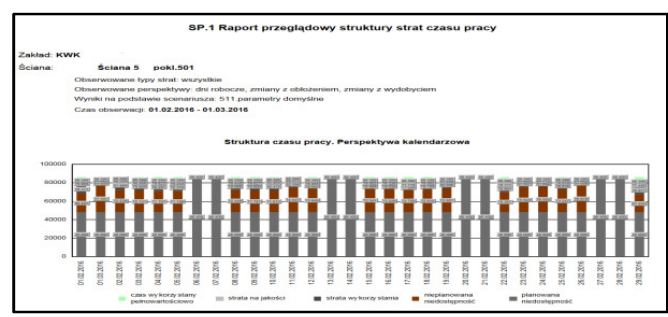

Fig. 2. Exemplary screens of developed support system 
As a result of the conducted analyzes, there were determined the partial and complex values of efficiency indicators for individual machines and the entire mechanized complex treated as a technical system. The research concerned a longwall shearer, longwall and undercut conveyors as well as a crusher. The presented results cover 22 working periods.

The results of preliminary studies clearly indicate, that the total value of effectiveness indicators of the investigated machines are low. In particular, this applies to a longwall shearer, which is the basic machine of this complex. Its low availability (on average around $58 \%$ ) meant, that in the considered period, the entire complex obtained very low efficiency (not exceeding $50 \%$ ). Further studies of the degree of utilization of these machines included determination of the reasons causing such low values of the analyzed indicators. The analyzes carried out, based on the recorded time series of machine operation parameters, clearly indicated that the main reason for this state are unplanned interruptions in the operation.

\section{THE LONG-TERM ASSESSMENT OF THE EXPLOITATION POLICY WITH THE USE OF TAXONOMIC METHODS}

The exploitation policy realized in the long-term period concerns the realization and assessment of operate and service works in the full exploitation cycle. For the purpose of supporting the decision-making process regarding the exploitation of machinery and equipment, the effects of which can be observed over a long time horizon, there was developed a quantitative way of the assessment of the exploitation policy with using taxonomic methods. Taxonomic methods allow to transform the values of features, describing in a distributed manner the various aspects of exploitation policy, into an aggregated variable being a resultant of exploitation processes (Fig. 3).

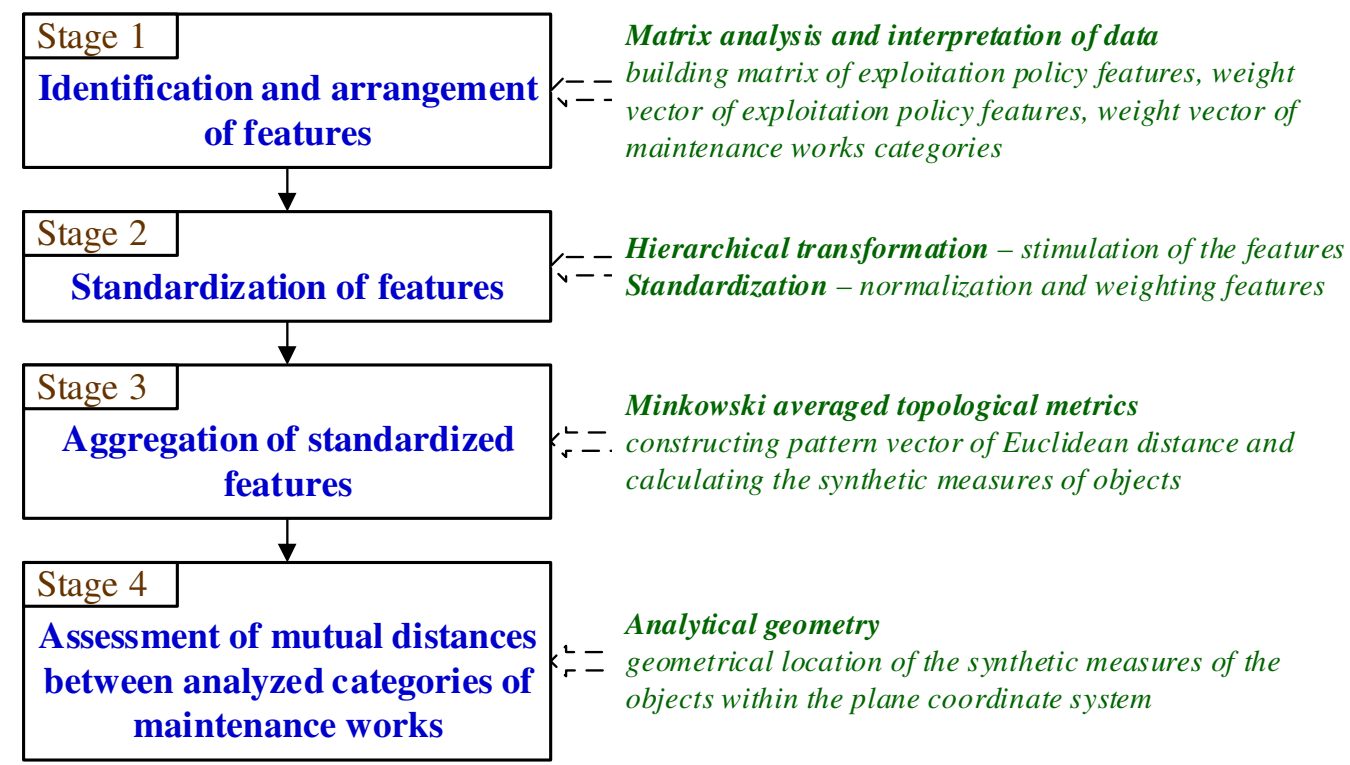

Fig. 3. The procedure for the construction of exploitation policy assessment model with using taxonomic methods and tools

Source: (Loska, 2017).

The developed method of assessment consisted in determining taxonomic synthetic measures and geometrical distances, on the basis of a multidimensional set of standardized and aggregated key features of various categories, These categories described the maintenance works for specific categories. The obtained values reflected the quantitative assessment of the realization of exploitation processes and they became the basis for the interpretation of the exploitation policy in a comparative approach. In the aspect of the above objectives, there was developed a method of assessment of the exploitation policy, including: 
- taxonomic model for assessing the exploitation policy,

- the procedure for generating positioning patterns,

- variant assessment of exploitation policy, based on the prepared data sets.

For the implementation of the developed taxonomic model, the SMOPE computer module was built. Its idea reflects the calculation and visualization of results, executed in two ways (separately for the analyzed technical system and patterns), taking into account the final variant statement. SMOPE is object-oriented, making it possible to link between the most important mechanisms. The objects are represented by layers separating structures of input data and result information and procedures (stages of supported tasks). In this way, it is possible to present SMOPE within the same pattern, both in structural and functional terms (Fig. 4).

Supporting activities carried out using SMOPE can be assigned to particular layers.

1. Data layer represents functions that allow for data acquisition for maintenance work structures, in accordance with the developed methodology. The applied procedures take on a parallel two-track character, enabling the definition of particular models, both in pattern or variant terms, as well as in relation to the exploitation policy of the analyzed technical system. The result of these tasks is the structure of maintenance work categories in the context of features of the exploitation policy (fig. 4a).

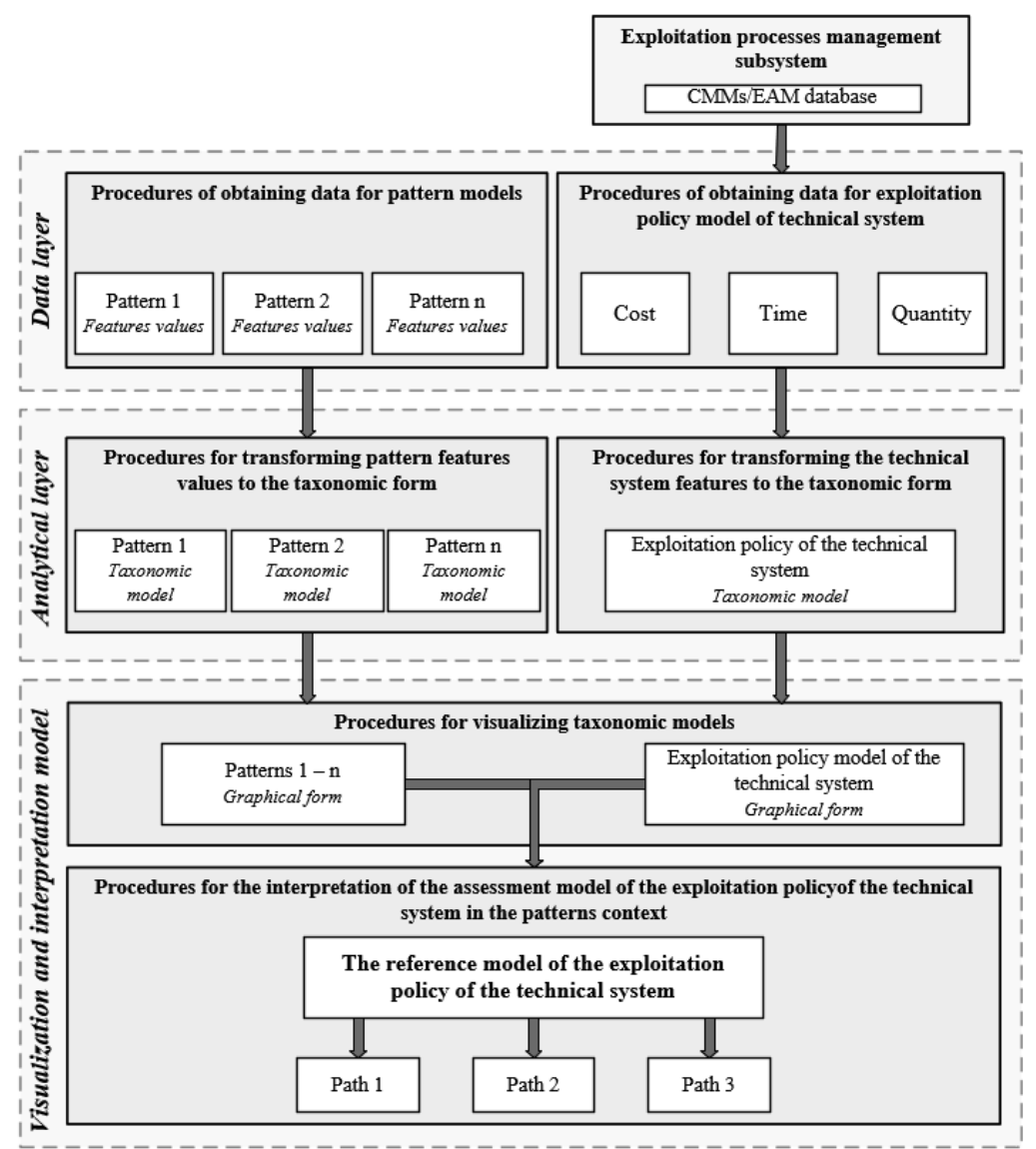

Fig. 4. Scheme of the SMOPE module (Loska, 2017)

2. The analytical layer represents functions aimed at computational implementation of the taxonomic model. The result of these tasks is a set of numerical sets of taxonomic measures (fig. $4 \mathrm{~b}, \mathrm{c}$ ).

3. The visualization and interpretation layer represents functions, aimed at presenting the results of the SMOPE activity (fig. $4 \mathrm{~d}$ ), in the form of a summary of the results of taxonomic 
calculations, both in static terms - in relation to the current moment, and dynamic - for future discrete moments in time.

The use of SMOPE enables the construction of reference models, that constitute a taxonomic comparison and the selection of the best-in-one exploitation path for decision-making process.

a.

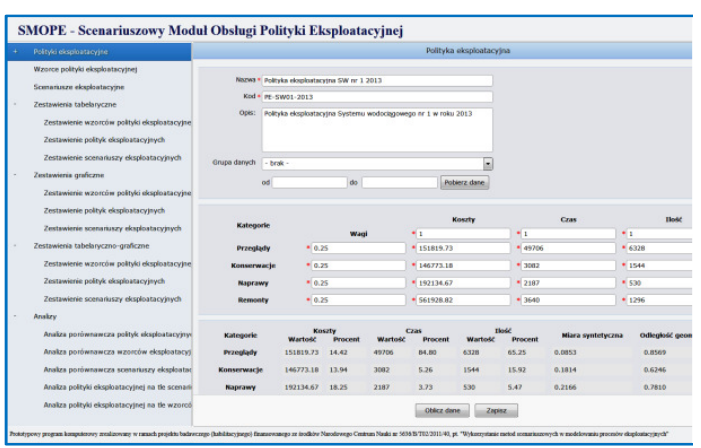

c.

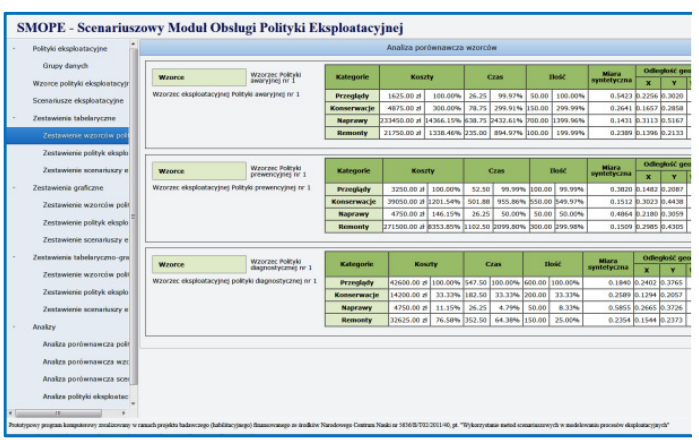

b.

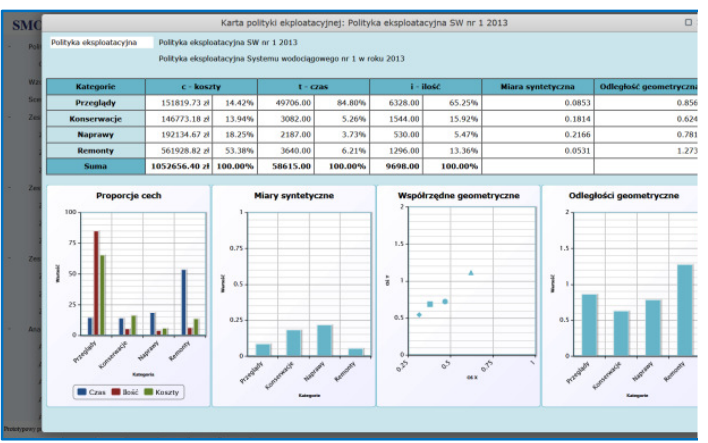

d.

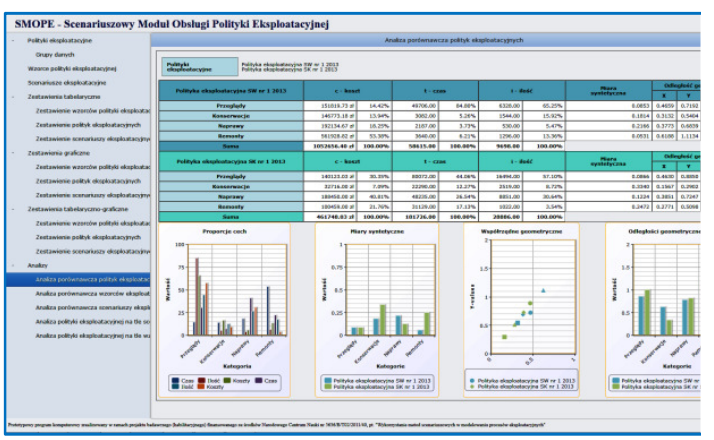

Fig. 4. Selected screens of the SMOPE module

\section{CONCLUSION}

The research results, presented in the article, confirm the possibility of identifying and describing the exploitation policy for different periods of the life cycle of technical objects. Application solutions are a practical interpretation of the developed methods, and also confirm the validity of the use of developed tools in industrial practice, as an important element of the Industry 4.0 concept.

\section{REFERENCES}

Antosz, K. (2018). Maintenance - identification and analysis of the competency gap. Eksploatacja i niezawodnosc - Maintenance and Reliability 20 (3), pp. 484-494.

Brodny, J. and Tutak, M. (2018). Use of IT platform in determination of efficiency of mining machines. E3S Web Conferences Volume 29, pp. E3S Web of Conferences eISSN: 2267-1242. Copyright/Published by: EDP Sciences; https://doi.org/10.1051/e3sconf/20182900014.

Burduk, A. (2013). Artificial Neural Networks as Tools for Controlling Production Systems and Ensuring Their Stability. Computer Information Systems And Industrial Management, Lecture Notes in Computer Science, Volume 8104, pp. 487-498.

Hermann, M., Pentek, T. and Otto, B. (2016). Design principles for Industrie 4.0 scenarios, Proceedings of the 49th Annual Hawaii International Conference on System Sciences, pp. 3928-3937.

Jasiulewicz-Kaczmarek, M., Wyczolkowski, R. and Gladysiak, V. (2017). Modeling a hierarchical structure of factors influencing exploitation policy for water distribution systems using ISM approach. IOP Conference Series-Materials Science and Engineering, Volume 282, Article Number: UNSP 012014.

Kagermann, H., Wahlster, W. and Helbig, J. (2014). Recommendations for implementing the strategic initiative Industrie 4.0: Final report of the Industrie 4.0 Working Group. National Academy of Science and Engineering, Berlin.

Karwot, J., Kaźmierczak, J., Wyczółkowski, R., Paszkowski, W. and Przystałka, P. (2016). Smart Water in Smart City: A Case Study. Proceedings of SGEM 16th International Scientific Conference on EARTH\&GEOSCIENCES, Book 3, Vol. I, pp. 851-858. 
Kosick, E., Kozlowski, E. and Mazurkiewicz, D. (2018). Intelligent Systems of Forecasting the Failure of Machinery Park and Supporting Fulfilment of Orders of Spare Parts. Advances in Intelligent Systems and Computing, Springer, Cham, Vol. 637, pp. 64-73.

Loska, A. (2017). Scenario modeling exploitation decision-making process in technical network systems. Eksploatacja i Niezawodnosc - Maintenance and Reliability, 19(2), pp. 268-278.

Loska, A. and Paszkowski, W. (2018). SmartMaintenance - The Concept of Supporting the Exploitation Decision-Making Process in the Selected Technical Network System. Advances in Intelligent Systems and Computing, Springer, Cham, Vol. 637, pp. 54-63.

Przystalka, P., Moczulski, W., Timofiejczuk, A., Kalisch, M. and Sikora, M. (2014). Development of Expert System Shell for Coal Mining Industry. Advances In Condition Monitoring Of Machinery In NonStationary Operations. Applied Condition Monitoring, Volume 4, pp. 335-348.

Stecuła, K., Brodny, J. and Tutak, M. (2018). Use of intelligent informatics module for registration and assessment of causes of breaks in selected mining machines. Poland Springer International Publishing AG, A. Burduk and D. Mazurkiewicz (eds.), Intelligent Systems in Production Engineering and Maintenance ISPEM 2017, Advances in Intelligent Systems and Computing 637, pp.74-84. DOI 10.1007/978-3-319-64465-3_8

Stecuła, K., Tutak, M. and Brodny, J. (2017a) Application of chosen elements from japanese production and maintenance management philosophies in polish coal mines. 17th International Multidisciplinary Scientific Geoconference SGEM 2017. Vol. 17, issue 13. Albena, Bulgaria 2017. pp. 93-100. DOI: doi.org/10.5593/sgem2017/13.

Stecuła, K., Brodny, J. and Tutak, M. (2017b). Informatics platform as a tool supporting research regarding the effectiveness of the mining machines' work. CBU International Conference Proceedings 2017: Innovations in Science and Education, Vol. 5, Prague 2017, p. 1215-1219. DOI 10.12955/cbup.v5.1099.

Szczesniak, B., Midor, K. and Zasadzien, M. (2017). A Concept of an IT Tool for Supporting Knowledge Transfer Among Facility Maintenance Employees as Part of Intelligent Organization. Advances in Intelligent Systems and Computing, Springer, Cham, Vol. 637, pp. 3-12.

Timofiejczuk, A. (2013). Context based diagnostics of rotating machinery. Surveillance 7. International conference, Chartres, France, October 29-30, 2013. Chartres: Institute of Technology, pp. 1-9.

Wachla, D., Przystałka, P., Kalisch, M., Moczulski, W. and Timofiejczuk, A. (2016). Development of expert system shell with context-based reasoning. Advances in Intelligent Systems and Computing, Volume 386, pp. 369-382. 